\title{
'Taoyuan No. 1': A High-yielding Batavia Lettuce Cultivar High in Total Phytochemicals and Dietary Fiber
}

\author{
Ah-Chiou Lee and Fang-Shin Liao \\ Taoyuan District Agricultural Research and Extension Station, Council of \\ Agriculture, Executive Yuan, No. 139, Sec. 2, Dongfu Road, Hsinwu, \\ Taoyuan County 32745, Taiwan \\ Hsiao-Feng Lo ${ }^{1}$ \\ Department of Horticulture and Landscape Architecture, National Taiwan \\ University, No. 1, Sec. 4, Roosevelt Road, Taipei, Taiwan
}

Additional index words. Lactuca sativa, single seed descent, early maturity, ascorbic acid, flavonoid, phenolics

Lettuce (Lactuca sativa L.) is one of the most important salad crops worldwide. In Taiwan, lettuce is primarily eaten as a cooked vegetable and has become increasingly popular. Concerning cultivation, lettuce is much less damaged by pests compared with other leafy vegetables; thus, the production has been increasing in recent years. To achieve high yield and good quality, lettuce is also grown in high tunnels, especially for organic production. Batavia lettuce and looseleaf lettuce are the main types grown. Landrace 'Fu San', which is adapted to high temperature, high humidity, and varied climate, is the only Batavia lettuce currently being grown in Taiwan. Other foreign commercial cultivars cannot compete with or substitute for ' $\mathrm{Fu}$ San'. However, 'Fu San' has two disadvantages: small plant size and slow growth rate. Developing a cultivar superior to ' $\mathrm{Fu}$ San' would be beneficial to lettuce production not only in Taiwan, but also in other subtropical areas.

Single-seed descent (SSD) is a method of plant breeding that has the advantage of obtaining homozygous lines in a much shorter time than conventional plant breeding methods by growing out multiple generations in the same year. The SSD method can be applied to self-fertilized species with high genetic variances for economic characters or crops for which self-fertilization is obligatory for commercial use (Brini, 1966; Fehr, 1987; Macchiavelli and Beaver, 2001). 'Taoyuan No. 1' was developed by the SSD method to promote vegetable production in high tunnels. This newly released cultivar with good quality and high yield is described.

Received for publication 20 Aug. 2012. Accepted for publication 23 Oct. 2012.

We thank T.C. Tsai and R.M. Hsu for technical assistance on this work and Asian Vegetable Research and Development Center for providing germplasm 'TOT423'.

${ }^{1}$ To whom reprint requests should be addressed; e-mail hflo@ntu.edu.tw.

\section{Origin}

'Taoyuan No. 1' was developed from a cross between 'Fu San' and 'TOT423'. 'Fu San' is a Batavia lettuce with a small plant type. 'TOT423' is a germplasm accession with high vigor collected from the Asian Vegetable Research and Development Center (Taiwan). The cross was made using the clipand-wash method of emasculation (Nagata, 1992) in a high tunnel at the Taoyuan District Agricultural Research and Extension Station (TYDARES, Taiwan) in Summer 2004. After the cross, 1560 randomly selected $\mathrm{F}_{2}$ plants were advanced to the $\mathrm{F}_{5}$ generation by the SSD method in the high tunnel in 2005 and 2006. Sixty-two superior single plants were selected based on the appearances of plants from the $\mathrm{F}_{5}$ generation. Sixteen single plants each $\left(\mathrm{F}_{5}\right.$-derived plant, $\left.\mathrm{F}_{5: 6}\right)$ were grown for a preliminary yield trial in Fall 2006 (temperature range 21 to $32{ }^{\circ} \mathrm{C}$ ). Commercial traits were evaluated from $\mathrm{F}_{5: 7}$ through $\mathrm{F}_{5: 11}$ in high tunnels in 2007 to 2009 as described subsequently. The best line, TYLT06G38, with high yield and good quality was designated 'Taoyuan No. 1' (Fig. 1) in 2009.

\section{Description}

'Taoyuan No. 1' has larger and greener leaves than 'Fu San' (Fig. 1). Leaves are longer than wide. Leaves become narrower toward the base. Leaf margins are mildly undulating and incised at the base. The leaf surface is savoy. The ribs are flat but become more pointed toward the base. The seed color is white, and there is slight purple pigmentation on the stem and hypocotyl. 'Taoyuan No. 1' can be harvested as looseleaf lettuce, but also forms a small head at maturity. The leaves are crisp and flavorful.

'Taoyuan No. 1' and 'Fu San', along with $18,8,8,2$, and 2 unselected breeding lines, were planted in trials in high tunnels at TYDARES on 26 Feb. 2007, 18 Sept. 2007, 25 Apr. 2008, 19 Sept. 2008, and 16 Apr. 2009 (temperature ranges, 14 to 28,20 to 32,18 to 31,22 to 32 , and 18 to $30{ }^{\circ} \mathrm{C}$ ), respectively.
Two trials were grown in each year following standard production practices. A randomized complete block design with four replicates was applied for each trial. Each plot was 2, 6, 6,12 , and $12 \mathrm{~m}$ long for each trial described previously separately with commercial spacing of $20 \mathrm{~cm}$ between plants and $20 \mathrm{~cm}$ between rows on an 80 -cm-wide quadruplerow bed. Ten plants per plot were randomly selected and evaluated for plant weight, number of edible leaves, area of fully expanded leaves measured with a LI-3100 Area Meter (LI-COR, Lincoln, NE), and relative chlorophyll content of leaves measured with a SPAD-502 Leaf Chlorophyll Meter (Minolta, Osaka, Japan). Measurements were made before 'Fu San' bolted ( 35 to $42 \mathrm{~d}$ after transplanting with a stem length of 0.5 to $1.2 \mathrm{~cm}$ ). SPAD measurements were made on fully expanded leaves and averaged over three readings per plant. The yield was calculated by weighing the plants in each plot and extrapolating the plot size to 1 ha. Data collected on these traits were analyzed using the general linear model procedure of SAS (SAS Institute, Cary, NC). The means were separated by a protected least significant difference test at $P \leq 0.05$. Superior lines were selected based on their performances in each trial for the subsequent trials during the five performance trials from 2007 to 2009 (data not shown). The data collected from 'Taoyuan No. 1' and 'Fu San' were outlined and compared using Student's unpaired $t$ test. The results of three years of replicated trials of 'Taoyuan No. 1' and 'Fu San' are shown in Table 1. The plant weight, yield, number of leaves, relative chlorophyll content, and single-leaf area of 'Taoyuan No. 1' were significantly higher than those of 'Fu San'.

Ten plants were used for the chemical analysis from each replicate of the trial in Apr. 2009. Fresh lettuce was rinsed in water to remove soil and then dried with paper towels. A whole individual plant, including inner and outer leaves from the base to the tip, was cut and mixed well. Subsamples of $20 \mathrm{~g}$ fresh lettuce per plant were used for the determination of total dietary fiber and ascorbic acid. To analyze $\beta$-carotene as well as total flavonoid and total phenolics contents, another subsample of $100 \mathrm{~g}$ fresh lettuce per plant was freeze-dried after first freezing to $-40{ }^{\circ} \mathrm{C}$ and finely ground. Total dietary fiber and ascorbic acid were analyzed according to AOAC methods 985.29 (AOAC, 2003a)

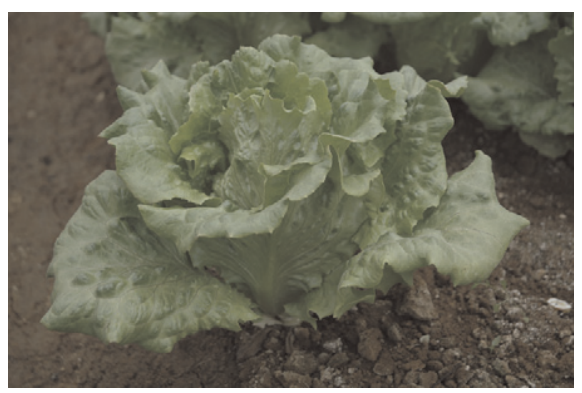

Fig. 1. Batavia lettuce 'Taoyuan No. 1' grown for $35 \mathrm{~d}$ after transplanting in a high tunnel. 
and 984.26 (AOAC, 2003b), respectively. $\beta$-carotene content was determined with high-performance liquid chromatography/ ultraviolet by comparing the retention time and spectra with those of a standard (Nicolle et al., 2004). The total flavonoid content was determined using a modified colorimetric method described previously (Meyers et al., 2003). The values were expressed as $\mathrm{mg}^{-1} \mathrm{~g}^{-1}$ of quercetin equivalents per fresh weight of lettuce. Total phenolics were analyzed by the Folin-Ciocalteu colorimetric method using gallic acid as a standard (Liu et al., 2007). Results were expressed as $\mathrm{mg} \cdot \mathrm{g}^{-1}$ of gallic acid equivalents (GAE) per fresh weight of lettuce. Data collected on the phytochemical contents of 'Taoyuan No. 1' and 'Fu San' were compared using Student's unpaired $t$ test. 'Taoyuan No. 1' exceeded 'Fu San' in total dietary fiber, $\beta$-carotene, total flavonoid, ascorbic acid, and total phenolics (Table 2).

In another experiment, seedlings with three true leaves of 'Taoyuan No. 1' and 'Fu San' were planted on 24 Feb. 2011 at TYDARES in a high tunnel for $42 \mathrm{~d}$. The temperature varied much during the growth period with the daily temperature range being 11 to $26^{\circ} \mathrm{C}$. A randomized complete block design with four replicates was applied. Each plot was $12 \mathrm{~m}$ long at the commercial spacing of $20 \mathrm{~cm}$ between plants and $20 \mathrm{~cm}$ between rows on an $80-\mathrm{cm}$-wide quadruple-row bed. Ten plants were harvested from each plot weekly and weighed individually. Graph preparation was performed with Sigmaplot 10 (Systat Software, San Jose, CA). Data in the graph were quoted as mean $\pm \mathrm{SE}$. The plant weight of 'Taoyuan No. 1' was consistently higher than that of 'Fu San' at 28 to $42 \mathrm{~d}$ after planting. At $35 \mathrm{~d}$ after planting, the plant weight of 'Taoyuan No. 1' had increased to nearly $150 \mathrm{~g}$, which is ready for marketing in Taiwan. However, it took $42 \mathrm{~d}$ for 'Fu San' to reach $150 \mathrm{~g}$, at which time 'Taoyuan No. 1' weighed $255 \mathrm{~g}$ and did not bolt. The result indicates that 'Taoyuan No. 1' matures earlier and is better adapted to the weather with temperature varying than 'Fu San' (Fig. 2).

\section{Seed Availability}

Taiwan Plant Breeder's Rights were granted by the Council of Agriculture, Executive Yuan, Taiwan, and R.O.C. Limited samples of seeds are available for research only by sending a request to the first author (e-mail: d95628003@ntu.edu.tw).

\section{Literature Cited}

AOAC. 2003a. Total dietary fiber in foods, enzymatic-gravimetric method. In: Horwitz, W. (ed.). Official methods of analysis of AOAC International. 17th Ed. Gaithersburg, MD.

AOAC. 2003b. Vitamin C (total) in food, semiautomated fluorometric method. In: Horwitz, W. (ed.). Official methods of analysis of AOAC International. 17th Ed. Gaithersburg, MD.

Brini, C.A. 1966. A modified pedigree method of selection in soybeans. Crop Sci. 6:220.

Fehr, W.R. 1987. Principles of cultivar development: Theory and technique. Macmillan, New York, NY.

Table 1. Plant weight, leaf number, leaf area, SPAD (relative chlorophyll content), and yield for 'Taoyuan No. 1' and 'Fu San' grown in high tunnels in trials at the Taoyuan District Agricultural Research and Extension Station from 2007 to 2009.

\begin{tabular}{|c|c|c|c|c|c|}
\hline Cultivar/line & Plant wt $(\mathrm{g})$ & No. of leaves $\geq 2 \mathrm{~cm}$ & Leaf area $\left(\mathrm{cm}^{2} / \mathrm{leaf}\right)$ & SPAD & Yield $\left(\mathrm{t} \cdot \mathrm{ha}^{-1}\right)$ \\
\hline \multicolumn{6}{|l|}{ Trial I, Feb. 2007} \\
\hline Taoyuan No. 1 & $191^{*}$ & $19.0^{*}$ & - & - & $25,186^{*}$ \\
\hline Fu San & 160 & 17.1 & - & - & 21,127 \\
\hline \multicolumn{6}{|l|}{ Trial II, Sept. 2007} \\
\hline Taoyuan No. 1 & $160 \mathrm{NS}$ & $20.3 \mathrm{NS}$ & $201 \mathrm{NS}$ & $30.6^{*}$ & 16,942 NS \\
\hline Fu San & 146 & 21.4 & 161 & 20.3 & 15,415 \\
\hline \multicolumn{6}{|l|}{ Trial III, Apr. 2008} \\
\hline Taoyuan No. 1 & $221 *$ & $27.8^{*}$ & $185^{*}$ & $34.7 *$ & $23,311 *$ \\
\hline Fu San & 161 & 22.5 & 162 & 26.8 & 17,028 \\
\hline \multicolumn{6}{|l|}{ Trial IV, Sept. 2008} \\
\hline Taoyuan No. 1 & $197 *$ & $25.8^{*}$ & $182 *$ & $27.1 *$ & $19,274^{*}$ \\
\hline Fu San & 185 & 24.4 & 161 & 20.7 & 16,974 \\
\hline \multicolumn{6}{|l|}{ Trial V, Apr. 2009} \\
\hline Taoyuan No. 1 & $220 *$ & $22.2 *$ & - & $30.9^{*}$ & $23,940^{*}$ \\
\hline Fu San & 165 & 18.0 & - & 23.7 & 19,866 \\
\hline
\end{tabular}

NS, * Nonsignificant or significant by $t$ test at $P \leq 0.05$.

Table 2. Contents of total dietary fiber, $\beta$-carotene, ascorbic acid, total flavonoid, and total phenolics in 'Taoyuan No. 1' and 'Fu San' grown in high tunnels in replicated trials at the Taoyuan District Agricultural Research and Extension in 2009.

\begin{tabular}{lccccc}
\hline Cultivar & $\begin{array}{c}\text { Total dietary } \\
\text { fiber }\left(\mathrm{mg} \cdot \mathrm{g}^{-1} \mathrm{FW}\right)\end{array}$ & $\begin{array}{c}\beta \text {-carotene } \\
\left(\mu \mathrm{g} \cdot \mathrm{g}^{-1} \mathrm{FW}\right)\end{array}$ & $\begin{array}{c}\text { Ascorbic acid } \\
\left(\mu \mathrm{g} \cdot \mathrm{g}^{-1} \mathrm{FW}\right)\end{array}$ & $\begin{array}{c}\text { Total flavonoid } \\
(\mathrm{mg} \text { QCE/g FW })\end{array}$ & $\begin{array}{c}\text { Total phenolics } \\
(\mathrm{mg} \mathrm{GAE} / \mathrm{g} \mathrm{FW})\end{array}$ \\
\hline Taoyuan No. 1 & 20 & 12.9 & 119 & 8.3 & 25.9 \\
Fu San & 17 & 7.2 & 86 & 6.8 & 22.0 \\
$t$ test & $*$ & $*$ & $*$ & $*$ & $*$ \\
\hline
\end{tabular}

*Significant at $P \leq 0.05$.

$\mathrm{FW}=$ fresh weight; $\mathrm{QCE}=$ quercetin equivalents.

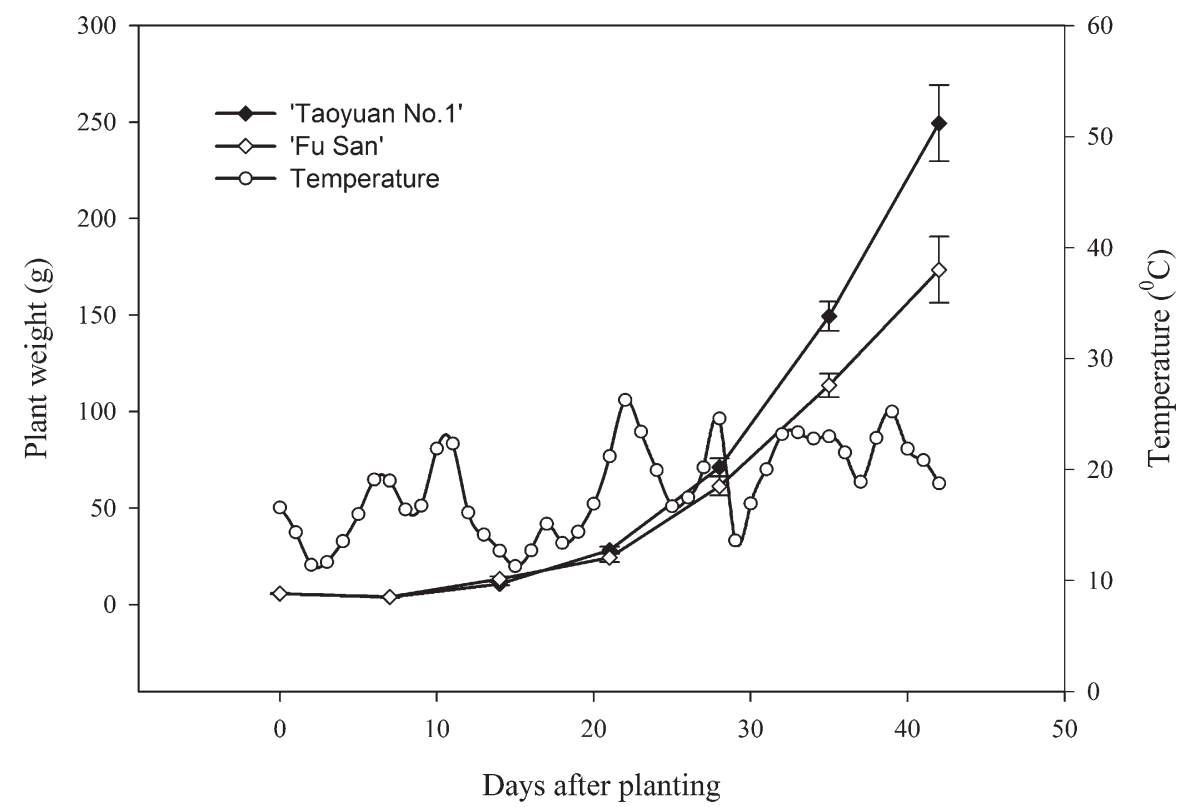

Fig. 2. Plant weights of 'Taoyuan No. 1' and 'Fu San' on seven harvest dates, sown on 26 Jan. 2011, transplanted on 24 Feb. 2011, and harvested on 6 Apr. 2011. Data are the mean \pm SE of four replicates of 10 plants.

Liu, X., S. Ardo, M. Bunning, J. Parry, K. Zhou, C. Stushnoff, F. Stoniker, L. Yu, and P. Kendall. 2007. Total phenolic content and DPPH radical scavenging activity of lettuce (Lactuca sativa $\mathrm{L}$.) grown in Colorado. LWT-Food Sci. Technolo. 40:552-557.

Macchiavelli, R. and J.S. Beaver. 2001. Effect of number of seed bulked and population size on genetic variability when using the multipleseed procedure of SSD. Crop Sci. 41:15131516.
Meyers, K.J., C.B. Watkins, M.P. Pritts, and R.H. Liu. 2003. Antioxidant and antiproliferative activities of strawberries. J. Agr. Food Chem. 51:6887-6892.

Nagata, R.T. 1992. Clip-and-wash method of emasculation for lettuce. HortScience 27:907-908.

Nicolle, C., A. Carnat, D. Fraisse, J.L. Lamaison, E. Rock, H. Michel, P. Amouroux, and C. Remesy. 2004. Characterisation and variation of antioxidant micronutrients in lettuce (Lactuca sativa folium). J. Sci. Food Agr. 84:2061-2069. 